\title{
THE QUALITY OF CARE AT THE INDEPENDENT MIDWIFERY CLINICS, SURABAYA
}

\author{
Indria Nuraini \\ PGRI Adi Buana University, Surabaya
}

\begin{abstract}
BACKGROUND: There have been an increasing number of independent midwifery clinics in Surabaya that received Bidan Delima award. However, anecdotal evidence from lay people indicated that some midwifery clinics were lacking in hospitality and reliability in the delivery of care. Some patients said that they lacked in communication and prompt decision making in obstetric emergency cases. This study aimed to assess the quality of care provided by the independent midwifery clinics in Surabaya.

SUBJECT AND METHODS: This was a qualitative study conducted in Surabaya, East Java. Five patients each from three independent midwifery clinics (BPM) in Surabaya were selected purposively for this study. The SERVQUAL dimensions of quality were chosen for criteria assessment, which included: (1) Reliability; (2) Tangible; (3) Responsiveness; (4) Empathy; (5) Assurance. The data were collected by in-depth interview, focus group discussion, direct observation, and document review. As a key informant, the patients were interviewed to give their opinions about the quality of care.

RESULTS: Health service quality provided by BPM has met the four dimensions of quality, including reliability, responsiveness, empathy, and assurance. Their services were fast and precise. The midwives were friendly and caring. The tangible dimension of quality, however, needs improvement. The entire informants were satisfied. Midwife services were perceived better than hospital services. The obstetric equipment used by the midwives has met the required standard. The informants expected that the BPM improve facilities, such as air conditioned rooms and parking lot. CONCLUSION: The patients generally perceive the quality of care provided by the independent midwifery clinics meet the reliability, responsiveness, empathy, and assurance, dimensions of quality. The tangible dimension needs improvement.
\end{abstract}

Keywords: quality of service, independent midwife clinics 